\title{
Intentionality vs. Psychophysical Identity
}

\author{
Denis Seron
}

(FNRS, University of Liège)

\author{
Université de Liège \\ Département de philosophie \\ Place du Vingt-Août 7 \\ B-4000 Liège (Belgium) \\ Phone +3243669516 \\ Fax +3243665559 \\ d.seron@ulg.ac.be
}

At least at first sight, there seem to be essential similarities between the philosophical doctrines of Ernst Mach and Franz Brentano. Both philosophers embraced a radical form of empiricism which quite plausibly deserves the name "phenomenalism". Both defended the view that external reality, viewed as a metaphysical issue, was something of a fiction or illusion. Both thought that empirical science should start by purging itself of all metaphysical assumptions. Just as Mach claims that "all metaphysical elements are to be eliminated as superfluous and as destructive of the economy of science" (Mach 1922: xxviii/xxviii), so Brentano, in his Psychology from an Empirical Standpoint, makes a call for a psychology that is free of the "metaphysical presuppositions" of the traditional theory of the soul (Brentano 1973: 27/18). ${ }^{1}$ Yet, in spite of these similarities, Brentano severely criticized a broad range of views that are central to Mach's philosophy. ${ }^{2}$

In this paper I discuss some core aspects of the dispute between the two authors. My starting hypothesis is that this dispute is a manifestation of a larger debate that played a central role in philosophy throughout the nineteenth century. As I will argue, Mach's psychophysical identity thesis as well as Brentano's theory of intentionality are best seen as contributions to the debate about the relationship between the mental and the physical. This is

\footnotetext{
${ }^{1}$ The second page number always refers to the English translation, if there is one.
}

2 The most extensive formulation of that critique can be found in (Brentano 1988). This book, edited by Chisholm and Marek, includes the whole correspondence and an essay on Mach's Knowledge and Errors which Brentano dictated in 1905-6. Some letters from Brentano to Mach had been previously published in (Thiele 1968: 294-296) and in (Brentano 1964). 
not merely a historical footnote. I think that Brentano's theory of intentionality is first of all a contribution to the psychophysical debate and should be regarded as such. For this reason, the Mach-Brentano controversy is key for understanding what is really at stake in Brentano's intentionality theory. For in this controversy Brentano explicitly presents his theory of intentionality as a variety of psychophysical dualism. ${ }^{3}$

\section{Some preliminary remarks}

To begin with, let us make some points on notable commonalities between the views of Mach and Brentano.

Franz Brentano's masterpiece, the Psychology from an Empirical Standpoint published in 1874 , is first and foremost an epistemological treatise. Its aim was to lay the foundations of a scientific, that is, empirical psychology — namely to define what an empirical psychology is or should be and to develop a method for it. As is well known, Brentano defines psychology as the "science of mental phenomena". The reason for this is explained on the opening pages of the first volume of his Psychology.

Traditionally, he declares, sciences are defined in reference to what kind of realities or substances they are about. Natural science is defined as the science of physical substances, namely of bodies. Likewise, Aristotle, Leibniz, Spencer, and Lotze define psychology as the science of mental substances, namely of souls (Brentano 1973: $21 \mathrm{ff} . / 14 \mathrm{ff}$.). Of course, empirical science as such must somehow deal with appearances. On the traditional view, however, appearances are not proper objects of knowledge. The actual objects of empirical science are bodies and souls, and bodies and souls are such that they can be known through their appearances in the mind. This is made possible by the fact that appearances stand in some special relation to reality. Physical phenomena are causal effects of bodies; mental phenomena are states or properties of souls. And both physical and mental phenomena must somehow be similar to their causes or substantial bearers.

Brentano rejects this traditional, indirect realist view. In his lecture on phenomenal green held in January 1893 before the Vienna Philosophical Society, he even declares that it has been "refuted by the progress of science" (Brentano 1979: 5). Phenomena, he claims, are the only objects of science. Natural science is not the science of physical reality, but the "science of physical phenomena"; psychology is not the science of the soul, but the "science of mental phenomena". His idea runs as follows:

\footnotetext{
${ }^{3}$ (Albertazzi 2002: 43) provides some hints in this direction.
} 
"But what entitles us to assume that there are such substances? It has been said that such substances are not objects of experience; neither sense perception nor inner experience reveal substances to us. Just as in sense perception we encounter phenomena such as warmth, color and sound, in inner perception we encounter manifestations of thinking, feeling and willing. But we never encounter a being of which these things are properties. Such a being is a fiction to which no reality of any sort corresponds, or whose existence could not possibly be proved, even if it did exist. Obviously, then, it is not an object of science. Hence natural science may not be defined as the science of bodies nor may psychology be defined as the science of the soul. Rather, the former should be thought of simply as the science of physical phenomena, and the latter, analogously, as the science of mental phenomena. There is no such thing as the soul, at least not as far as we are concerned, but psychology can and should exist nonetheless, although, to use Albert Lange's paradoxical expression, it will be a psychology without a soul." (Brentano 1973: 15-16/10-11) ${ }^{4}$

As a matter of fact, Brentano endorsed the project of a "psychology without a soul". At the end of the same section, he most explicitly argues that the modern definition of psychology as the science of mental phenomena is better than the old definition of psychology as the science of the soul, because, among other things, the latter "contains metaphysical presuppositions from which $<$ the former $>$ is free" (Brentano 1973: 27/18).

Remarkably, Brentano here defends a view which closely resembles Ernst Mach's phenomenalism. First, both Mach and Brentano are phenomenalists insofar as they hold that phenomena are the only acceptable objects of science. Secondly, Mach also regards substances as fictions. "The thing and the ego", he claims, "are provisional fictions of the same kind" (Ding und Ich sind provisorische Fiktionen gleicher Art) (Mach 1926: 15/9; cf. Brentano 1988: 18). Thirdly, Mach, too, in Knowledge and Error, explicitly embraces

\footnotetext{
${ }^{4}$ I have slightly modified the English translation because it is manifestly influenced by Oskar Kraus's interpretation, which I think is wrong. Kraus's inability to hear, or willful blindness to, what Brentano actually says in this quote is properly unbelievable. Brentano explicitly says that "neither sense perception nor inner experience reveal substances to us". Yet Kraus maintains that this is not Brentano's own view, and that, for Brentano, "both sensation and inner perception exhibit substances to us". Brentano claims that the "being" (das Wesen ) "of which < mental phenomena $>$ are properties", so the soul or mental substance, "is a fiction to which no reality of any sort corresponds" (eine Fiktion, der keinerlei Wirklichkeit entspricht). Kraus maintains that it is not "the assumption that there is a substance" which is a fiction, but "the assumption that there is an attribute without any subject supporting it" (Brentano 1973: 258/11)!
} 
Lange's idea of a "psychology without a soul" (Mach 1926: 12/8). According to his famous dictum, the ego or soul - Mach uses the two words interchangeably (Mach 1922: 4/5) — is "unsalvageable" (das Ich ist unrettbar) (Mach 1922: 20/24). Fourthly and finally, Mach, like Brentano, opts for phenomenalism because the realist option is fraught with unscientific metaphysical presuppositions. As Mach often emphasizes, the purpose behind his reductionism is to eliminate "philosophical pseudo-problems" due to ungrounded metaphysical hypotheses (Mach 1922: 22/28; Mach 1926: 12/12; cf. Brentano 1988: 23). ${ }^{5}$

The question I wish to address concerns the relationship between the philosophical programs of Mach and Brentano at the most general level. My view is that these programs, although strikingly similar, are radically opposed in their approach to the psychophysical issue. In my estimation, the difference is between psychophysical monism and dualism. On the one hand, Mach's psychophysical identity thesis asserts a psychophysical monism. On the other hand, as I will suggest, Brentano endorses a form of psychophysical dualism, and this dualism is actually his theory of intentionality itself. In his notes on Knowledge and Error, Brentano is very clear on the fact that the most fundamental disagreement between Mach and him is over the psychophysical difference. He claims that "the break with dualism", which he credits to Spinoza, "is full of absurdities", and that Mach's psychophysical identity thesis is actually a "regression to a level below" that of modern psychology and even commonsense (Brentano 1988: 47-48). ${ }^{6}$

\section{The psychophysical identity thesis}

As is well-known, the psychophysical problem was one of the most intensely debated issues in the nineteenth century philosophy. Cartesian metaphysical dualism seemed to be definitively abandoned at that time, and most philosophers embraced substance monism: reality consists of just one type of substance. Metaphysical materialists like Carl Vogt, Jacob Moleschott, and Ernst Haeckel claimed that reality consists only of physical substances, or bodies, or matter. Metaphysical "spiritualists" or "panpsychists", for example Fechner and Lotze, claimed that reality consists only of mental substances, or souls.

\footnotetext{
${ }^{5}$ It is true, however, that Brentano, in his 1905-06 dictation on Knowledge and Error, attacks this view by pointing out that it leaves no room for philosophy at all (Brentano 1988: 23ff.). This is an interesting aspect of Brentano's critique and one that deserves special attention - but it would take us too far from our main concerns to discuss it here.

${ }^{6}$ In a letter to Husserl dated 26 December 1893, Brentano rather oddly seems to reject both monism and dualism: "If I manage to refute monism, I hope I will then be able to demonstrate the implausibility of dualism as well and to advocate a view that is infinitely different from both" (Husserl 1994: 14-15).
} 
However, this is not the most interesting part of the debate. Much more interesting are the discussions on mental and physical phenomena. The question is whether it is relevant to distinguish between the two and, if so, what sort of relation they have to each other. This question is crucial if one takes for granted, as many philosophers of the time did, that science must be empirical, that is, deal not with substances, but with phenomena. Science, unlike metaphysics, is not concerned with how the world really is, but with how it appears to be. Lotze and Fechner, for example, were both metaphysical monists and phenomenological dualists. The former affirms that substances, namely mental substances, are accessible only through intellectual intuition, and that intellectual intuition pertains not to science, but to poetry and religious faith. The scientist, by contrast, confines herself to studying relations between phenomena, especially causal relations between physical phenomena and between mental and physical phenomena. Now, Lotze criticizes materialists for being committed to a phenomenological monism that ignores the qualitative difference between mental and physical phenomena (Seron 2015: 25-26). In spite of his metaphysical spiritualism, Lotze devotes a significant part of his Medical Psychology of 1852 to arguing for the irreducibility of the psychophysical difference. Quite unexpectedly, he even goes so far as to defend Descartes against materialists.

Lotze's view is best seen as a metaphysical monism combined with a phenomenological (or scientific) dualism. In short: Lotze states both the substantial identity and the qualitative difference of mental and physical phenomena. Of course, other combinations are possible, but what is important here is that the two issues - the metaphysical and the phenomenological are independent of each other.

In some respects, Fechner's psychophysical parallelism is very similar to Lotze's conception. Fechner, too, endorses some form of metaphysical spiritualism and claims that mental and physical phenomena form two distinct series. However, his explanations are ambiguous and may be interpreted differently. Fechner claims that mental and physical phenomena are appearances of one and the same being and that they belong to two phenomenologically different types. But he also says that this difference is just a matter of "standpoint" (Standpunkt der Betrachtung). By this he means that the only difference between both kinds of phenomena is that mental phenomena are objects of inner experience, while physical phenomena are objects of outer experience (Fechner 1860: 5-6; 1877: 67). For this reason, Lotze criticized him for disregarding the qualitative differences between the mental and the physical and thus falling back, like materialists, into phenomenological monism (Seron 2015: 38).

In a sense, Mach's psychophysical identity thesis represents a further step in the same direction. First, Mach views the metaphysical mind-body problem as a pseudo-problem and, like Brentano, he sweeps it away under the carpet. Secondly, he defends a phenomenological monism according to which there is no constitutive qualitative difference between mental and 
physical phenomena. There is only one phenomenal world, in which each phenomenon should be viewed as both mental and physical at the same time. The alleged difference between mind and body, claims Mach, actually lies in functional relations between sensations.

Interestingly, Mach explicitly appropriates psychophysical parallelism as a monist theory (see Mach 1922: 50 ff./60 ff., 305). Fechner's parallelism, he argues, says that (1) phenomena are either mental or physical, that (2) mental and physical phenomena are distinct facets of one and the same reality, and that (3) mental and physical phenomena are interrelated by relations of functional dependence. ${ }^{7}$ Mach rejects the first two theses and endorses the third. First, his version of parallelism holds that each phenomenon is not either mental or physical, but both mental and physical at the same time. This is the psychophysical identity thesis. Secondly, Mach explicitly emphasizes that his theory is not a metaphysical or philosophical theory of how the world really is (Mach 1926: 13/13). He certainly accepts the idea that mental and physical phenomena are aspects of one and the same third, but he denies that this third is an unknowable substance, a thing in itself (Mach 1926: 13/13). In other words: the third must consist of sensation. Thirdly, talk of mental and physical phenomena is just a misleading way of talking about functional relations among sensations. The relation between the mental and the physical is not such that, in order for it to obtain, its terms must be of different natural kinds, mental or physical. Rather, it is the relation itself that makes a sensation mental or physical.

\section{The theory of intentionality as a phenomenological dualism}

Brentano's philosophy of mind is diametrically opposed to Mach's monism of sensation. Brentano's position, like Mach's, can in some sense be called a "phenomenalism". As said earlier, however, Brentano's phenomenalism is combined with a strong form of phenomenological dualism which as such makes it incompatible with Mach's phenomenological monism. My suggestion in what follows is that Brentano's phenomenological dualism is identical to his theory of intentionality.

At first glance, there may seem to be no unbridgeable difference between Brentano's theory of intentionality and Mach's characterization of the mind-body relation as a relation of functional dependence. After all, Brentano's tenet is that physical phenomena should be viewed as intentional contents, and intentional contents are dependent parts of mental acts. Of course, one may object that, in Brentano's view, this dependence relation is one-sided only,

\footnotetext{
${ }^{7}$ On Mach's debt to Fechner, see also (Mach 1922: xxvii/xxxvi).
} 
while Mach views it as two-sided. But the objection is not really compelling. We could point out that, according to Brentano, the dependence relation between the primary and the secondary object of the mental act is two-sided. The primary object of the mental act is necessarily dependent on its secondary object, and vice versa.

Additionally, Brentano's idea of an intentional in-existence of the object in the mental act may look similar to Avenarius' notion of "introjection", which Mach appropriates for his own account of the distinction between the mental and the physical (Mach 1922: 42-43/5152). For Mach as well as Brentano, the distinction between the representing subject and the represented object is, so to speak, locative. For Brentano, a represented object is a phenomenon that is intentionally contained within another phenomenon. For Mach, a represented object is a sensation that is enclosed within the spatial boundaries of the representing subject's body (Mach 1926: 5 ff./4 ff.).

So, where is the disagreement? The most prominent difference is that Brentano takes "mental" and "physical" as denoting natural kinds. This is a very general feature of his methodology of philosophy. As he says at the beginning of the second volume of the Psychology, "scientific study must have classification and order, and these may not be arbitrary. They ought, as far as possible, to be natural, and they are natural when they correspond to a classification of their subject-matter which is as natural as possible" (Brentano 1925: 3/177). Likewise he claims, some pages further on: "A scientific classification (...) must be natural, that is to say, it must unite into a single class objects closely related by nature, and it must separate into different classes objects which are relatively distant by nature." (Brentano 1925: 28/194) Much of the 1874 Psychology is devoted to working out a criterion for distinguishing mental from physical phenomena. Mental phenomena differ from the others in virtue of some natural feature, namely the intentional in-existence of an object in them.

For Mach, by contrast, the words "mental" and "physical" do not denote natural kinds. As he declares in The Analysis of Sensation, "the boundary-line between the physical and the mental is solely practical and conventional" (Mach 1922: 254/311). Mental and physical phenomena are made out of the same stuff, namely sensations, and it is only their mutual relations that constitute them as physical or mental, things or egos. This is exactly how Carnap puts the matter in Section 164 of the Aufbau, where he attacks the intentionalism of Brentano and his followers. It is false, he says, to pretend that the obtaining of an intentional relation depends on the nature of the terms that stand in that relation. Thus, "the intention relation is not a relation of a unique kind which can be found nowhere but between a psychological entity and that which is represented in it" (Carnap 1998: 227).

In marked contrast with this view, Brentano's theory of intentionality is best seen as a form of psychophysical dualism. Like Lotze, Brentano holds that mental and physical 
phenomena are by nature qualitatively or intrinsically different. Their difference lies in the fact that all mental phenomena, unlike physical phenomena, have an intentional content. This difference is "natural", insofar as it is somehow derived from experience. As Brentano puts it, a classification is "natural" if, and only if, it "proceeds from a study of the objects to be classified and not from an a priori construction" (Brentano 1925: 28/194). The intentional relation — the fact that some phenomena have an intentional content — is not a mere stipulation, it is something that we experience, something that we somehow discover or learn from inner experience. And this discovery as such does not preclude the possibility that other criteria of the mental will be discovered in the future. As Brentano explains, in the text "Vom Objekt" dating from 1906, the same year as the dictations on Knowledge and Error:

"Having an object is a general feature of everything mental, as it appears in our experience. What this means cannot be clarified (deutlich machen) without a hint about the experience; this would be impossible just as it is impossible for a blind person to clarify the concept of red, for someone that is never loved or hated to clarify the concepts of love and hatred (...)." (Brentano 1966: 339)

\section{Two objections}

We now come to two key objections raised by Brentano to the psychophysical identity thesis - objections which may as well be viewed as arguments in support of phenomenological dualism. These two objections are of a very general character. But for the sake of clarity I will start with a more specific objection which is actually, as I will try to show, a particular case of the second objection. This more specific objection is about concepts. It is presented in the dictations on Knowledge and Error and in the 1906 text just quoted.

Mach's theory of concept is expounded in Chapter 8 of Knowledge and Error and in Chapter 14 of The Analysis of Sensation. It is, basically, a genetic theory. Roughly: the subject associates present or remembered experiences on the basis of similarities, selects such-andsuch feature in accordance with her needs (practical, scientific or otherwise), and finally creates a concept which is no more than a sensation "impulse". A concept, says Mach, is "a simple impulse to perform some familiar sensory operation, as the result of which a definite sensational element (the mark of the concept) is obtained" (Mach 1922: 263/322). For example, the concept of red is not a representation. Red in general is not something that can be represented (Mach 1922: 262-263/321-322). It is just an impulse to imagine or remember this or that red thing. 
For Brentano, this amounts to denying the generality of concepts - or to affirming that there can be no such things as concepts in the traditional sense of the word:

"For Mach, we have only individual sensations and representations, of which all the rest, including concepts, is composed. The first assertion already rules out that there are concepts in the traditional sense of the word." (Brentano 1988: 56; cf. Brentano 1966: 337-338)

Brentano's argument is as follows: Mach takes concepts to be reducible to sensations; now, sensations are by definition individual, and Mach himself undoubtedly agrees with this; therefore, Mach takes concepts to be individual, which contradicts the traditional view of concepts. Since the view that concepts are individual is obviously absurd, the view that concepts are reducible to sensations must be absurd as well.

Brentano plausibly regarded this view as so central to Mach's philosophy as his psychophysical monism. And of course he rejected it as so absurd as psychophysical monism. Additionally, and interestingly, it seems that Brentano considered both views - monism and concept reductionism - to be closely interconnected. ${ }^{8}$ And I think he had good reasons for this, which will become apparent later.

Let us now examine the two objections alluded to above. My conviction is that the problem generated by Mach's view of concept is part of a more general problem which is inherent in psychophysical monism in general, and that Brentano's theory of intentionality precisely aims to overcome this more general problem.

Before proceeding further, it is useful to return to Brentano's theory of intentionality. Phenomena are objects of presentation (Vorstellung). In Brentano's sense, a presentation is a direct acquaintance with something that appears, or is given to, the subject. It is the appearance of something in one's mind: "As we use the verb 'to present' (vorstellen), 'to be presented' means the same as 'to appear"” (Brentano 1973: 114/81); "We speak of a presentation whenever something appears to us" (Brentano 1925: 34/198). Accordingly, a presentation is not a representation in the contemporary sense of the word, that is, an intentional act or state. Physical phenomena are presented and yet have no intentional content: they are not "intentional" in the contemporary sense. Dermot Moran (2000: 45) rightly

\footnotetext{
${ }^{8}$ See for example (Brentano 1988: 28): "The identification of the act of seeing with colors, of the act of hearing with sounds, of the presentation of a tree with the tree, is false and absurd. Mach has not even given an apparent demonstration of that absurd view; also missing is anything that can be viewed as an apparent demonstration of the fact that a scientific concept is nothing but a compound of sensible presentations, a compound which is of an individual character as are sensations."
} 
stresses that for Brentano a presentation is more like an "idea" in the sense of Locke and Hume, namely a mere phenomenal datum.

Among the subject's presentations, some are perceptions. Perception involves more than mere presentation. A perceived phenomenon not only appears, it must necessarily appear with a character of real, present existence; it is accepted or believed in (anerkannt). Brentano calls the phenomena that are perceived "secondary objects", and the phenomena that are not perceived "primary objects". The basic idea of his theory of intentionality is twofold. First, all secondary objects are mental, so mentality is a necessary condition for real existence. Secondly, primary and secondary objects are by nature such that the former are phenomenally contained within the latter. In other words: a primary object is the content of a mental phenomenon - a content which does not exist really but only intentionally, hence a phenomenon which "in-exists" or merely appears within a mental phenomenon that really exists. This is what we contemporary philosophers call "intentionality". As is well-known, Brentano never used the word "intentional" in the contemporary sense of intentional directedness; he rather speaks of the mental act's "relation to a content". This relation to a content is simply a phenomenal relation in virtue of which something that does not exist appears within a mental phenomenon which is innerly perceived and really exists.

What motivations led Brentano to this view? I think he had two more basic reasons or arguments, and that these arguments are precisely those which he uses against Mach's psychophysical identity thesis.

The first argument, which can be found in Chapter 10 of the dictation on Knowledge and Error, is about inexistent objects. The idea is that the psychophysical identity thesis makes it impossible to account for representations without object. Indeed, this thesis entails that the represented object and the act of representing it are identical. Thus, if the act of representing an object $A$ exists, then the object $A$ must necessarily exist as well. Therefore, a representation of an object that does not exist is impossible:

"Mach sees no difference between the presentation and the presented object, the act of seeing and the seen object, the act of remembering and what is remembered. Thus, from his point of view, isn't the existence of the presented object as certain as that of the act of presenting it? (...) Of course it can be that one waits for something that never happens; but for Mach it would not be the case; for, in his view, the act of waiting is that which is awaited, and if the act of waiting occurs, then that which is awaited occurs as well. For him, who writes about Knowledge and Error, error is simply impossible." (Brentano 1988: 68) 
Is Brentano's objection justified? It would for sure hold if Mach had asserted that the represented object and the act of representing it were numerically identical. But this is not what Mach actually says. Mach's actual view is that the two are type-identical. The relation between the two as individuals is not token-identity, but type-identity with functional dependence. The intentional relation is a dependence relation between phenomena of the same type, namely sensations. Nevertheless, there is a looser sense in which Brentano's first objection may be valid, and this brings us to the second objection. If presented or represented objects are sensations, and if one construes Mach's sensations as objects of perception, as Brentano did, then it seems impossible for them not to exist, or not to be accepted as existent. For being perceived involves really existing, or being accepted as really existing. That is why Brentano, in the same chapter, addresses the case of negative judgments. In the case of negative judgments, the presented content is rejected as non-existent. Therefore, it cannot be perceived, it must be represented in another mode than the perceptual.

In my view, one of the most fundamental aims of Brentano's theory of intentionality is to provide a general basis that would ensure the possibility of non-perceptual representations — including conceptual thoughts — within an empiricist framework. This is made possible by the distinction between primary and secondary objects, which is the very core of the theory of intentionality. The secondary object, namely the mental act I presently experience, must be perceived and, as such, really exist. By contrast, the primary object, namely the intentional correlate, is not perceived. It is presented, it appears in the mind, and this appearing has a variety of modes: for example it is remembered, imagined, accepted or rejected, thought, loved or hated, etc.

Plainly, some intentional acts have an object that does not exist. To put it otherwise: not all phenomena really exist. For this to be possible, there have to be presentations that are not perceptions. For perception involves real existence. Therefore, Mach's claim that all phenomena are reducible to sensations is false. Besides the objects of perception - that is, primary objects, the mental phenomena I presently experience - , there must be phenomena that appear without existing, that is, merely "intentional" contents. This is what "intentionality" (in the contemporary sense) is all about: something that does not exist appears within a mental phenomenon that exists.

Given this, it is no surprise that, in the 1906 essay on the object, Brentano's main objection against Mach is that he absurdly tries to eliminate the distinction between primary and secondary objects and the related distinction between direct and oblique modes (Brentano 1966: 337-338). The objection is as follows: Mach grants real existence only to individuals; since concepts, as traditionally conceived, are not individuals, they do not really exist; and 
they do not even exist in the mind, for the mind is part of what really exists. To this, Brentano objects that being in the mind does not entail really existing:

\footnotetext{
"When one says that something is in the mind, one does not mean by this that something really is, but that there is something that has a presentation of it, or has it as its object." (Brentano 1966: 338)
}

In short: a concept, like any other intentional content, is something that appears in the mind and does not exist. As opposed to the secondary object, the primary object is something that is presented or thought only in an oblique mode, that is, in a non-referential way or, as Brentano puts it, without being accepted (cf. Brentano 1966: 340).

\section{References}

Albertazzi, L. (2002). Phenomenologists and Analytics: A Question of Psychophysics? The Southern Journal of Philosophy, 40 (2002), p. 27-48.

Brentano, F. (1925). Psychologie vom empirischen Standpunkt. Vol. 2: Von der Klassifikation der psychischen Phänomene. Leipzig: Meiner. English transl.: Psychology from an Empirical Standpoint (A.C. Rancurello, D.B. Terrell, \& L.L. McAlister, Transl.). London New York: Routledge.

Brentano, F. (1966). Die Abkehr vom Nichtrealen. Hamburg: Meiner.

Brentano, F. (1964). Einige Briefe an Ernst Mach: Franz Brentano an Mach. In: K.P. Heller: Ernst Mach. Wegbereiter der modernen Physik. Wien: Springer, p. 157-159.

Brentano, F. (1973). Psychologie vom empirischen Standpunkt. Hamburg: Meiner. English transl.: Psychology from an Empirical Standpoint (A.C. Rancurello, D.B. Terrell, \& L.L. McAlister, Transl.). London New York: Routledge.

Brentano, F. (1979). Untersuchungen zur Sinnespsychologie (R.M. Chisholm \& R. Fabian, Eds.). Hamburg: Meiner.

Brentano, F. (1988). Über Ernst Machs „Erkenntnis u. Irrtum“. Mit zwei Anhängen: Kleine Schriften über E. Mach. Der Brentano-Mach-Briefwechsel, R.M. Chisholm \& J.C. Marek (Eds.). Amsterdam: Rodopi.

Carnap, R. (1998). Der logische Aufbau der Welt. Hamburg: Meiner.

Fechner, G.T. (1860). Elemente der Psychophysik. Leipzig: Breitkopf und Härtel. 
Fechner, G.T. (1877). In Sachen der Psychophysik. Leipzig: Breitkopf und Härtel. Reprint Saarbrücken: Verlag Dr. Müller, 2006.

Husserl, E. (1994). Husserliana Dokumente, Vol. 3: Briefwechsel, Part 1: Die Brentanoschule, Dordrecht: Springer.

Mach, E. (1922). Die Analyse der Empfindungen und das Verhältnis des Physischen zum Psychischen (9 ${ }^{\text {th }}$ edition). Jena: Fischer. English transl. (1959): The Analysis of Sensations and the Relation of the Physical to the Psychical (C.M. Williams, Transl.). New York: Dover.

Mach, E. (1926). Erkenntnis und Irrtum: Skizzen zur Psychologie der Forschung (5 ${ }^{\text {th }}$ edition). Leipzig: Barth. Reprint (2002), Berlin: rePRINT, Parerga. English transl. (1976): Knowledge and Error: Sketches on the Psychology of Enquiry (T.J. McCormack \& P. Foulkes, Transl.). Dordrecht: Reidel.

Moran, D. (2000). Introduction to Phenomenology. London, New York: Routledge.

Seron, D. (2015). Lotze et la psychologie physiologique. In: Lotze et son héritage : Son influence et son impact sur la philosophie du XX siècle (F. Boccaccini, Ed.). Brussels: Peter Lang.

Thiele, J. (1968). Briefe deutscher Philosophen an Ernst Mach. Synthese, 18/2-3, 285-301. 